\title{
Investigating an effective supply chain for a refinery in a regulated petroleum sector \\ CADENDORF, ${ }^{,} F$ EMUZE ${ }^{2}$ AND $V$ KHULU
}

\begin{abstract}
Currently, refined petroleum products are manufactured by six refineries in South Africa. The supply of refined petroleum products is supplemented by imports of refined petroleum products. These refined petroleum products are transported by pipeline, rail, road, sea and a combination thereof to depots across the country. These products are then distributed directly to commercial customers through points of resale in the form of retail service stations. The challenge is that the storage facilities and distribution networks in South Africa are currently utilised to its full capacity. There is a need to expand current storage infrastructure or to erect new storage facilities to facilitate imports. Durban Port that currently handles $70 \%$ of the country's crude oil and $40 \%$ of refined products is also utilised to its full capacity. The investigated problem pertains to the limited storage and transport capacity available for the distribution of petroleum products in the country. The interview protocol, which was based on the literature reviewed, was used for compiling the primary data for the case study. Selected findings revealed that the respondents perceived that storage capacity is the most significant constraint militating against adequate supply by the supply chain. The findings also indicated that the respondents were of the opinion that transport rates and routes (cost of logistics) are the greatest contributor to the prices of products. As a result, there appears to be a major scope for improvement in terms of the usage of pipelines and rails for the movement of petroleum products.
\end{abstract}

Keywords: Petroleum products, storage facilities, supply chain, transportation, South African energy sector.

Disciplines: civil engineering, architecture, business studies, energy studies.

\section{Background}

This research aims to investigate the development of effective supply chain systems in order to create value for end users in South Africa. A firm is currently studying the establishment of

1. Chris Adendorf $\mathrm{PhD}$ is Adjunct Professor, NMMU Business School, Nelson Mandela Metropolitan University, PO Box 77000 Port Elizabeth, 6031, South Africa .Email: powerhouse@alfresco.co.za.

2. Fidelis Emuze $\mathrm{PhD}$, is Senior Lecturer, School of Civil Engineering and Built Environment, Central University of Technology, Free State, Private Bag X20539, Bloemfontein, 9300, South Africa. Email: femuze@cut.ac.za.

3. Vukani Khulu MBA, NMMU Business School, Nelson Mandela Metropolitan University, PO Box 77000, Port Elizabeth, 6031, South Africa. Email: Graham.Ward@nmmu.ac.za. 
a new crude oil refinery in Port Elizabeth and the design of storage locations around the country in order to distribute its products effectively throughout the country. In order to distribute the fuel products from the refinery in a cost effective manner, the firm has to choose the geographic location, number and size of new storage facilities to be built, and in some cases share existing storage with other firms.

The primary objective of this study is geared towards the investigation of how the firm can develop the distribution network for their proposed crude oil refinery in such a way that the firm can achieve improved competitiveness and profitability. The new refinery will have significant changes in the size and location of demand of fuels from the firm. The study is intended to assist logistic designers to develop distribution networks. This is based on the premise that mathematical models that are underpinned by qualitative data could lead to the development of logistics support systems required by large-scale fuel distribution networks. It is necessary to conduct the research as production, inventories, employment, revenue, profit and a host of other indicators fluctuate irregularly but persistently throughout the economy, from one industry to the other (Sterman, 2006).

In other words, supply chain instability harms firms, consumers, and the economy through excessive inventories, poor customer service, and unnecessary capital investment. In particular, this case study is based on the assumption that a refinery would be built in Coega at Port Elizabeth. Although there have been delays due to financial problems, South Africa's state-owned oil company PetroSA contend it was still committed to the refinery project according to a media release available on the Coega Development Corporation (CDC) website. The media release that was published on the $25^{\text {th }}$ October 2011 indicates that PetroSA was still committed to building a 400000 barrels per day refinery at the port of Coega in order to replace old and aging plants and also reduce the country's reliance on importation. However, a major problem of the proposed refinery would be that it is not connected to an inland pipeline network, and therefore, products for consumption outside its immediate consumption area would have to be transported to Durban by sea and then piped to inland locations.

\section{Review of related literature}

In 2007 the South African Petroleum Industry Association (SAPIA) noted that South Africa may face increased importation of petroleum products and therefore refining capacity should be increased in the country (Swanepoel, 2007). For instance, Cooper (2007) opined that about $60 \%$ of South Africa's liquid fuel requirements are imported as crude oil for local refining. Having insufficient refining capacity to meet demand is not in itself a problem, as the product can be sourced form international refineries (Cooper, 2007). However, the challenge is in having sufficient infrastructure to move the product from one location to another (Bell, 2006 cited by Cooper, 2007).

The growing popularity of the supply chain concept has prompted increasing collaboration among supply chain partners with respect to demand forecasting. Such collaboration can enhance efficiency by reducing overall inventory levels in a supply chain (Simchi-Levi et al., 2000). Heungjo, Wilhelm and Searcy (2011) suggest that most operational level studies of the petroleum based fuel supply chain addressed the operations at refineries. They argued that reducing inventory levels through constant flow of products to the points of need could improve operational efficiency and profits. In this context, Neiro and Pinto (2004) proposed a 
general modelling framework for the operational planning of sub-facilities within a refinery. For example, processing units that modify the material physically or chemically, tanks for mixture and storage of the different feed streams, and pipelines for transportation of crude oil and products, were cited by them. They prescribe material flow through each process step and then, incorporate operational constraints to represent practical features associated with the refining process.

Regardless of the model type, the basic design problem in any production and distribution network is to match supply and demand at the output points of the system in the most economic way. The supply chain infrastructure typically needs to be re-evaluated due to changes in demand patterns, product mix, production processes, sourcing strategies, or the cost of running facilities. In addition, mergers and acquisitions may mandate the integration of different logistics networks (Simchi-Levi et al., 2000). It is clear that the delivery of products to where they are needed required efficient transport and storage facilities within a supply chain system. The next sections therefore briefly address storage and transportation related issues.

\section{Storage depot terminal management}

Storage depot terminal refers to places where inventory can be stored for a particular period of time. Depot terminals may be established at each production plant or located strategically near the markets; their size will depend upon the demands for specific items, and this will determine the number required. For consumer products, local retail outlets are usually the end of the distribution line; however, most local retailers are primary display and selling locations that were bypassed by distributors. Changing the number and location of warehouses will change the number of customers who are close to them, that is, product availability. This will in turn change the costs of warehousing and carrying inventory (Coyle, Bardi \& Langley Jr, 2003).

It's often said that the success of a retail store depends on three factors: location, location, location. It can also be said that the success of a particular logistics system is dependent upon the location of the relevant warehousing and production facilities. Facility location decisions are increasingly important as the configuration of logistics systems is altered due to the impacts of multinational trade agreements (Simchi-Levi et al., 2000). Facility location is a logistics / supply-chain activity that has evolved from a tactical decision to one of tremendous strategic importance in numerous organizations. Facility location is studied in terms of sitting distribution centres, warehouses (depots), and production facilities in ways that accommodate the movement of inventories to customers. The location of warehouses (depot terminal) facilities to serve retail outlets is also important in terms of cost savings and the ability to efficiently manage the production and flow of materials along the supply chain. The major factors influencing location decisions are markets and resource availability as most facilities are located near one or the other. Labour and transport services are two other key factors in facility location. The transportation system makes other resource factors mobile and allows a firm to combine factors of production that originate great distances apart (Simchi-Levi et al., 2000).

Throughput is a measure of the volumes of goods passing through a warehouse in a given time period, and it affects the design and layout. For example, a low through-put requires maximum space utilization for storage, while a high throughput should be capable of rapid information processing and materials handling. Tradeoffs must balance the disadvantages 
against the advantages more or less through space allocation, mechanization and turnover of stocks. Space may be an advantage at times, but horizontal storage racks will vary according to the throughput (Coyle et al., 2003). Layouts must take into account the type of materials handling equipment (loading and offloading facilities) to be used, whether order-picking and stock-replenishing have to occur at the same time, how arrivals and departures are organized, or whether operations are labour inter-designed so that it can benefit from computerized controls (Coyle et al., 2003).

In essence, the firm must balance the cost of opening new warehouses with the advantages of being close to the customer (Simchi-Levi \& Simchi-Levi, 2002). Thus, warehouse location decisions are crucial determinants of whether the supply chain is an efficient channel for the distribution of products (Bhatnagar \& Teo, 2009; Snyder, Daskin \& Teo, 2007). The design objective represents a minimization of the total distribution cost associated with all three decision components; facility locations, inventory parameters and transportation selection (Shen \& Qi, 2007; Shu, Teo \& Shen, 2005). It also represents multiple transportation options and explicitly requires that demands of customer outlets for all products are satisfied by open distribution centres Tsiakis \& Papapgeorgious, 2008.

\section{Transportation management}

Ronen (1995) observed that refineries produce light products in the form of gasoline, kerosene, diesel oil, aviation fuel and heavy products. Ronen (1995) then explained types of operational environments encountered in practice: light products transported in bulk from refineries to tank terminals and industrial customers; and light products from tank terminals to retail outlets. He proposed two scheduling formulations that are important for a refinery operator: set strategies for minimising cost and set strategies for maximising profits. Thus, transportation is an essential element of any strategy that could lead to the evolution of competitive advantage in this context. In particular, most studies of downstream operations have addressed designing the network (strategic) and prescribing material flow (tactical) (Heungjo et al., 2011).

Transportation can be defined as the actual physical movement of goods or people from one place to another, while transportation management (traffic management) refers to the management of transportation activities by a particular organisation. Transportation is often the most costly logistics activity, and can range from $40 \%$ to $60 \%$ of a firm's total logistics costs (Simchi-Levi et al., 2000). Freight transport is an inescapable cost in the supply function of consignors and consignees so much so that firms usually seek to minimise it whenever possible. Economies of scale exist when an expanded level of output results in reductions in the total unit cost of transport (per ton-kilometre). Therefore, with increasing output the fixed cost per unit of output declines faster than the variable cost increases per additional unit output.

These transport management strategies can contribute to the attainment of economies of scale, that is, increase vehicle size and maximum utilisation of capacity (Potter, Towill \& Disney, 2007). According to Potter et al. (2007), whenever demand growth can be sustained, incremental expansion of infrastructure may result in substantial return of scale. With rail transport, the move from a single-track to a double track system may quadruple line capacity by eliminating directional conflict and a quadruple track may increase track may increase capacity even more if it allows segregation by speed. Engineers involved with petroleum refining and pipeline transport capacity extension use so called two-third rule: the capacity of 
any facility can be doubled at only two-thirds increase in cost. An outbound journey automatically gives rise to an inbound journey. This implies that if a full load is hauled, backhaul will be cheaper as the vehicle must return to the point of origin as rooted in the reverse logistics concept (Bernon \& Cullen, 2007). The achievement of the economies of scope usually requires standardised or at least compatible technology that can accommodate product diversification. This implies one must be able to share technology between two or more users and spare capacity must be available to accommodate product diversification (Chouinard, D'Amours \& Ait-Kadi, 2007).

\section{Modes of transportation}

According to Coyle et al. (2003), modes of transportation that support logistics systems are not limited to road, rail, pipeline and the sea. Features of some of these modes include (Coyle et al., 2003):

- Road transport with increased vehicle size and fleet size may result in increased economies of scale. Infrastructure such as terminals, particularly for specialised carriers, provides further economies of scale. Other potential sources of economies of scale are specialised vehicles, owning a workshop for vehicle maintenance and repairs, specialisation in terminals, and management efficiency. Road transport can achieve economies of scope by consolidating consignment effectively. Owning to the high ratio of variable costs to total costs of individual vehicles, and the relatively small terminal facilities, road transport does not enjoy significant long-haul economies;

- In some countries, ownership of rail infrastructure and of train operations was organisationally divorced. Any prospective rail transport operator may gain open access to existing rail infrastructure and tracks under certain prescribed conditions. A rail transport operation may, through economies of density, enjoy natural monopoly on a particular route. The combination of long distance haulage, double-track operation with increased frequency of trains, and capacity loads (also back haul) on long trains may lead to significant unit cost advantage;

- On the principle of economies of density, an increase in pipe diameter can result in a lower unit cost. An uninterrupted and prolonged throughput of a large volume of homogeneous product increases economies of density. Because of the capital cost of a pipeline the barriers to entering the market is high. Owing to the inflexibility in capacity limit of a pipeline once installed, a new method of moving the product has to be found once the pipeline reaches its capacity; and

- Ocean shipping competition ranges from open competition, as in the case of tramp shipping (individual shipping seeking cargo), to oligopolistic cartels, as in the case of linear shipping conferences. A linear shipping complex is a number of ships from various shipping lines working on a route in conference, or sharing the loads on the route. Economies of scale are possible with large individual vessels and not necessarily with large fleet operations, therefore owners of tramp ships, are therefore able to compete with larger scheduled conference liners. 


\section{Methodology}

The emphasis in this research project was placed on a case study, where a more detailed investigation is carried out to gain a deeper understanding of specific situations. The project was also based on perceptions that could be presented in words. The idea is not necessarily to draw statistical conclusions or comparisons on the success of distribution networks in a business, but rather, it is to make an extensive evaluation of how petroleum products can be stored and transported to different points of sale.

Case study is usually a selection of a specific organisation, which is profiled in terms of the relevant issues under research (Leedy \& Ormrod, 2005). The objective of most case study research projects is to gain varied opinions or perspectives of the organisations' situation and processes. Participants that were interviewed were selected from different levels within the same industry. Though the respondents seemed to agree on a number of issues, they also differed on others. Informed consent and confidentiality of responses were assured when undertaking the field work.

Considering the nature of the project, semi-structured interviews were deemed to be the ideal methods of collecting information from the participants of the study. 21 respondents that are working in the petroleum distribution sector participated in the study. Of the 21 respondents, 18 were male while 3 were female. All the respondents were either middle level or top level management employees of their organisations. Their job titles range from supply and logistics / or operations manager to chief executive officer (CEO). It is notable that 14 participants of the study have over 15 years of industry experience, while 6 of them have between 5 and 15 years of industry experience. The next section descriptively presents the views of the respondents.

\section{Results and discussions}

When asked about demand forecasting related questions, 94\% of the respondents were of the opinion that storage capacity constraints constitute a significant challenge in the supply chain; $67 \%$ of them agreed that customer base and demand for products have a huge influence on storage facility layout; $87 \%$ opined that road and rail gantry do not have an impact on the fixed cost of a storage tank; and $76 \%$ agreed that CAPEX for storage tanks contribute significantly to the total distribution costs of petroleum products. The response was in line with the reviewed literature in terms of storage facilities (Coyle, Bardi \& Langley Jr, 2003). In particular, the findings corroborate the perception that storage facilities and distribution networks in South Africa are currently utilised to its full capacity. The split related to the 'customer base and demand for products' findings could be understood to show that facilities can either be established at each production plant or located strategically near the markets. The results concerning CAPEX confirms what the literature noted in that when managing inventory, logisticians need to simultaneously consider three relevant costs- the cost of carrying (holding) product, the cost of ordering product, and the cost of being out of stock (Simchi-Levi et al., 2000). In other words, inventory was perceived as a major contributor to the costs of running a storage facility.

In terms of transport related issues, $93 \%$ of the respondents agreed that transport rate and route is a major contributor to product price; $66.7 \%$ of them contend that the parcel size of loads of petroleum products affect shipment costs; $66.7 \%$ of them said that they would not 
utilise road transport if rail was available; and $80 \%$ of the respondents perceive that the lead times for fuel delivery have an impact on distribution costs. Table 1 indicates the respondents' perceptions of certain transport related statements in terms of response percentages ranging from 1 (strongly disagree), 2 (disagree), 3 (neutral), 4 (agree) to 5 (strongly agree) and a mean score (MS) ranging between 1.00 and 5.00. It is notable that the majority of the response percentages were above the neutral point, which indicates that in general the respondents agreed with the statements. In particular, $57.2 \%$ of the respondents strongly agreed that the availability of transport mode is important when choosing a location for storage tanks, while $66.7 \%$ of them also strongly agreed that rationalising ports of call could reduce the unit cost of shipping products. Furthermore, $66.7 \%$ of the respondents strongly agreed that slot charter could reduce the shipping rate instead of each partner 'goes it alone' shipping method, while less than half of them (47.6\%) strongly agreed that shipment load size differs from one province to another.

\section{Table 1: Respondents' rating of transport related issues}

\begin{tabular}{|c|c|c|c|c|c|c|}
\hline \multirow[t]{3}{*}{ Statement } & \multicolumn{6}{|c|}{ Response (\%) } \\
\hline & \multirow[b]{2}{*}{$\stackrel{0}{\leftrightarrows}$} & \multicolumn{5}{|c|}{ Strongly disagree...Strongly agree } \\
\hline & & 1 & 2 & 3 & 4 & 5 \\
\hline $\begin{array}{l}\text { Availability of transport mode is important } \\
\text { when choosing a location for storage tanks }\end{array}$ & 0.0 & 0.0 & 4.8 & 9.6 & 28.6 & 57.2 \\
\hline $\begin{array}{l}\text { Rationalising ports of call could reduce the unit } \\
\text { cost of shipping products }\end{array}$ & 0.0 & 0.0 & 4.8 & 9.6 & 19.0 & 66.7 \\
\hline $\begin{array}{l}\text { Slot charter could reduce the shipping rate } \\
\text { instead of "goes it alone" shipping method }\end{array}$ & 0.0 & 0.0 & 4.8 & 4.8 & 23.8 & 66.7 \\
\hline Shipment load size differs between provinces & 0.0 & 0.0 & 4.8 & 23.8 & 23.8 & 47.6 \\
\hline
\end{tabular}

Nevertheless, $76.2 \%$ of the respondents perceive that there is no major price difference among shipping operators, although $66.7 \%$ of them contend that they rarely see stranded ships used for fuel supply. When responding to storage tanks related issues, $85.7 \%$ of the respondents were of the opinion that competition in the ownership of storage tanks is weak in South Africa. Granted that the competition is weak, storage tank owners have no control or limited influence on the price of products due to the regulated environment according to 19 respondents. In fact $71.4 \%$ of the respondents contend that they would say that 'regulated prices have influenced investments related to storage tank facilities.'

When asked if the coordination of transportation and storage endeavours concerning distribution could reduce the overall distribution cost, $66.7 \%$ of the respondents answered in the affirmative. However, the question related to what could be done to improve the fuel 
distribution in South Africa generated different intervention from 18 respondents. These interventions that were offered in the form of general comments inter-alia, include:

- Increase the tank capacity for storage;

- Development of the NMPP: new terminal in Coega should be linked with a network of rail and develop rail network to support regions not covered by the NMPP;

- Optimising storage capacity and utilisation of ports facilities for fuel imports;

- NMPP will greatly improve fuels distribution from coastal to inland. Trucking of fuels will be decreased and distribution costs to inland areas will also decrease. Rail transport will have to be improved in order to further reduce trucking of fuels. This will also reduce costs of fuels in the inland area;

- Improve rail infrastructure/reliability and have common rail gauge across South Africa. Reduce road transport costs since these are sensitive to movement in oil prices. Capacity of inland depots is strained there is scope to expand here to minimise risk of stock outs;

- More pipelines; improved rail facilities; improved import infrastructure;

- Consolidation into common access terminals at certain national locations;

- Investment in new fuel depots, investment in distribution pipelines, investment in new forecourts in previously disadvantaged communities and transport of fuels from distribution gantries to garages;

- South Africa is extremely short of commercial storage capacity, let alone capacity for strategic stock, which is almost non-existent. All potential investments such as project Mthombo, NMPP, will require additional storage capacity along the DBN - JHB corridor in order to run optimally and effectively, giving adequate service to customers as well as factoring future growth. So the opportunity is massive. Future winners will be those that choose to invest in logistics infrastructure. Multinational oil companies are not guaranteeing future capital expenditure. Most of them are already exiting Africa not because of a lack of opportunities but simply not wanting to spend in Africa anymore. So Africans have to take this opportunity with pride and determination, focusing not on short term gains but long term economic development for generations to come;

- Upgrade of the rail network and rationalising of the depot network;

- Integrated Infrastructure development i.e. Pipeline, rail and minimal usage of road transport, and

- Integrated pipelines stemming from refineries to major customers and distributors in the long-term may optimize fuels distribution costs.

\section{Recommendations}

The firm that acted as the case study has a vision of becoming the leading energy company in Africa. In order to support this goal, it is recommended that the firm invest in integrated logistics support systems so as to distribute products from the proposed new crude refinery to the market.

\section{Storage facility}

It is recommended that the firm increase their storage terminal / depot infrastructure capacity to handle imports of fuels, which at the later stage will be for handling the products produced 
by the new crude refinery to be built in Port Elizabeth. It is suggested that the firm should consider having a hub storage depot in Port Elizabeth and in Jameson Park (Johannesburg) where the new pipeline will interconnect to other distribution network. Other small depots suggested for the firm to consider are Cape Town and Durban. Concerning Coega Terminal, it is recommended that the firm should build distribution tanks closer to the port. It is recommended that this maritime tank farm be interconnected to the one inside the refinery. The main purpose will be to handle coastal loadings for the new refinery. Initially the facility will serve as an import facility for refined products until the new refinery is established. The firm should operate facilities with other oil companies in accordance with universal access criteria to third parties on excess capacity.

It is recommended that the firm builds a road and rail gantry within the maritime tank farm mentioned above. The rail will have to be integrated to the Transnet marshalling yard in Coega where intermodal or cross-docking into railway can take place. To be succinct, it is recommended that the firm should endeavour to refurbish existing tank-farms; and the firm may also consider building additional tanks in the refinery to handle the importation requirements for the area.

\section{Transport for inland fuel}

The two most favoured modes of transport are pipeline and rail. It is much cheaper to transport fuel through pipeline and rail. The 16 inch multi-product pipeline between Johannesburg and Durban due to be completed in 2013 is recommended so as to ensure sustainable and efficient fuel supply while easing congestion on one of Africa's busiest road corridors. The pipeline will replace the existing 12 inch Durban to Johannesburg pipeline, which is nearing the end of its lifespan. The dedicated inland pipeline was running at maximum operational capacity and is unable to increase throughput (Cooper, 2007), hence an increase in the pipeline size from 12 inch to 16 inch is commended. The pipeline is expected to reduce the number of fuel tankers on the road by at least $60 \%$, thereby reducing high road costs. Multi-product pipeline will be the cheapest and faster means of moving petroleum products as it achieves economies of density, that is, the increased size of pipe diameter will result in lower unit costs. It is suggested that the firm request for an allocation on this new pipeline in advance and factor it into their fuel distribution strategy in order to gain competitive advantage. The firm is advised to maximise utilisation rate of the pipeline in order to substantially reduce their distribution costs for target markets.

In addition, rail capacity has been identified as an area that could increase throughput for inland markets. Currently, Transnet Freight Rail has 204 rail freight cars, which were in operation as well as block trains that were essentially the same. They also had 32 rail tankers, which they offloaded twice per day at the airport. Rail is the only reasonable mode of transport where throughput can be adjusted easily to accommodate drastically increased fuel requirement and also easily adjustable should this trend be reversed. This makes it an important and the most optimal mode of transporting jet fuels for airports during peak times. This can be seen with the ease at which fuel supply was adjusted during world cup by increasing rail freight cars and rail tankers to ORTIA to meet the peak demand of fuels over a short period. It is recommended that the number of the rail tank cars as well as block trains be increased incrementally to meet inland market forecasted demand. It is advised that additional offloading facility to match increased rail tank cars be considered in the design for a railway distribution network. It is also suggested that the combination of long distance haulage, increased capacity loads on long trains may lead to significant unit cost advantages 
for the firm. Because supply constraints on oil, both from an infrastructure and a resource perspective, could place increasing pressure on the transport systems in South Africa (especially in Gauteng) (Cooper, 2007), the use of pipeline and rail network should be increased.

Products from the firm's refinery in Coega to Durban and Cape Town will have to be transported by ship. The products will then be sent through the pipeline to inland markets. Cost saving can be achieved in shipping through strategic partnership with other oil companies in areas such as equipment sharing for loading and offloading, joint marketing and space sharing on ships through slot charters and consortia. Another opportunity for the firm will be to rationalize port of calls and intensified asset utilisation, both in terms of vessel utilisation and container deployment. Strategic partnership with ocean carriers will help the firm to vertically integrate shipping into land based activities such as pipeline and terminals. This seamless distribution is important in order to achieve speedy delivery of petroleum products to the terminals.

\section{Conclusion}

The findings of the study in terms of an integrated network distribution configuration is intended to act as a catalyst that could enable the movement of products from the proposed Coega refinery to designated markets. In addition, it is anticipated that they would create a new fully integrated additional income stream for the firm and will also allow to the firm to substantially increase its profile and footprint within South Africa.

With respect to fuel distribution networks, the literature reviewed and the primary data of the study corroborate the perception that there is limited storage capacity in South Africa. While regulations from the department of energy will affect storage capacity related issues, the firm should ensure that it pursues policies that support the availability of rail and pipeline infrastructure necessary for distribution of products from the refinery.

\section{References}

Bernon, M. \& Cullen, J. (2007) An integrated approach to managing reverse logistics. International Journal of Logistics Research and Applications, 10, 41-56.

Bhatnagar, R. \& Teo, C. (2009), Role of logistics in enhancing competitive advantage: a value chain framework for global supply chains. International Journal of Physical Distribution and Logistics Management, 39(3), 202-226.

Chouinard, M., D’Amours, S. \& Ait-Kadi, D. (2007) Design of reverse logistics networks for multiproducts, multistates, and multiprocessing alternatives. In: Jung, H; Chen, F.F. \& Jeong, B. (editors) Trends in supply chain design and management: technologies and methodologies. Berlin: Springer, pp. 181-212.

Cooper, C.J. (2007) Energy and transport issues for Gauteng, South Africa. Journal of Energy in Southern Africa, 18, 11-15.

Coyle, J.J., Bardi, E.J. \& Langley Jr., C.J. (2003) The management of business logistics: supply chain perspective. $7^{\text {th }}$ edition. Mason: South-Western.

Heungjo, A., Wilhelm, W.E. \& Searcy, S.W. (2011) Biofuel and petroleum-based fuel supply chain research: a literature review. Biomass and Bioenergy, 35, 3763-3774. 
Leedy, P.D. \& Ormrod, J.E. (2005) Practical research: planning and design. $8^{\text {th }}$ ed. New Jersey: Pearson Prentice Hall.

Neiro, S.M.S. \& Pinto, J.M. (2004) A general modelling framework for the operational planning of petroleum supply chains. Computer Chemical Engineering, 28, 871-896.

Potter, A., Towill, D.R. \& Disney, S.M. (2007) Integrating transport into supply chains: vendor managed inventory (VMI): In: Jung, H; Chen, F.F. \& Jeong, B. (editors) Trends in supply chain design and management: technologies and methodologies. Berlin: Springer, pp. 331-344.

Ronen, D. (1995) Dispatching petroleum-products. Operations Research, 43, 379-387.

Shen, Z.M. \& Qi, L. (2007), Incorporating inventory and routing costs in strategic locations models. European Journal of Operational Research, 179(2), 372-389.

Shu, J., Teo, C. \& Shen, Z.M. (2005), Stochastic transportation-inventory network design problem. Operations Research, 53(1), 48-60.

Snyder, L.V., Daskin, M.S. \& Teo, C. (2007) The stochastic location model with risk pooling. European Journal of Operational Research, 179(3), 1221-1238.

Simchi-Levi, D., Kaminsky P. \& Simchi-Levi, E. (2000), Designing and managing the supply Chain. Concepts, Strategies and Case Studies. $3^{\text {rd }}$ edition. Boston: McGrawHill.

Simchi-Levi, D \& Simchi-Levi, E. (2002), The effect of e-business on supply chain strategy. MIT-ESD Working Paper Series. Boston: MIT.

Sterman, J.D. (2006) Operational and behavioural causes of supply chain instability. In: Torres, O.A.C. \& Moran, F.A.V. (editors) The bullwhip effect in supply chains: a review of methods, components and causes. London: Pelgrave-Macmillan, pp. 17-56.

Swanepoel, E. (2007) SA facing permanent import of fuel - Sapia [online] Available from: http://www.engineeringnews.co.za/ [accessed 12 December 2010] 